\title{
Joseph Petzval lens design approach
}

José Sasián

José Sasián, "Joseph Petzval lens design approach," Proc. SPIE 10590, International Optical Design Conference 2017, 1059017 (27 November 2017); doi: $10.1117 / 12.2285108$

SDIE Event: International Optical Design Conference - IODC 2017, 2017, Denver, United States 


\title{
Joseph Petzval lens design approach
}

\author{
José Sasián \\ College of Optical Sciences, University of Arizona \\ 1630 E. University Blvd., Tucson, Arizona USA 85721
}

\begin{abstract}
We pose that there is enough information left to reconstruct Petzval lens design approach, and answer the question of how Joseph Petzval design his famous portrait objective.

Keywords: Joseph Petzval, landscape objective, portrait objective, lens design, aberration theory, photographic lens

\section{INTRODUCTION}

Joseph Maximillian Petzval (1807-1891) was a talented mathematician and physicist from Hungary who immigrated to Austria and taught at the University of Vienna. He designed the lens that made portrait photography a practical reality. It is said that the Petzval portrait lens was the first photographic lens that was calculated, rather than put together by trial and error. There is no document left by Petzval that describes how he performed his lens designs. A detailed analysis of Petzval's lens design approach has not been discussed in the literature. However, we pose that Petzval, Peter W. F. Voigtländer, and Anton Martin left enough information to reconstruct Petzval's approach to lens design which is the subject of this paper. The main question we answer is how Petzval designed his famous portrait objective.
\end{abstract}

\section{SOURCES OF INFORMATION}

The analysis presented below relies on the following documents:

1. Petzval report of 1843 [1].

2. Petzval report of 1857 [2].

3. Voigtländer letter which includes the original objective prescription and excerpts by J. Petzval and A. Martin, 1858 [3].

4. Josef Eder's books $[4,5]$.

5. P. Pretsch translation into the English language of a Petzval letter, 1858 [6].

6. R. Kingslake description of the Petzval-Voigtländer conical brass camera [7].

\section{PETZVAL PRESCRIPTION}

After the announcement of Daguerre's photographic process in August of 1839 it was clear that optically fast lenses were needed to reduce photographic exposure time. Petzval was asked by his colleague Andreas Ettingshausen to understand the shape of the lenses used in photographic cameras [1].

"It was in the year 1839, when the wonderful invention by Daguerre was made public, and incited the general interest to such a high degree. At that time I was first made aware of the strange shape of the objectives used in Daguerre's camera obscura by my dear friend and colleague Professor von Ettingshausen. I was asked to explore the reason for this shape."”

*It is known that the objectives used by Daguerre were achromatic plane-convex-lenses. Their plane side was turned toward the object, the convex side towards the image. They have an opening of 3 zoll, but this opening is reduced to 1 zoll by a diaphragm placed before at a distance of 3 zoll from the lenses. 
By May of 1840 Petzval, who was then 33 years old, had designed two objective lenses, one for "views" photography working at F/9.19 and another for portrait photography working at F/3.67. These two lenses were manufactured by P. W. F. Voigtländer and tested by A. Martin [3]. A partial prescription of the lenses has survived as it was disclosed in the proceedings between Petzval and Voigtländer. A notarized copy of the original lens prescriptions is given by Voigtländer [3]. The constructional parameters are given in three ways, in linien units, in zoll units, and in linien and zoll units; these are obsolete German units. There is some ambiguity between the inch and the zoll and here we take 1 zoll equal to $11 / 32$ inch. Petzval provided prescriptions for two sets of objectives. Table 1A provides the prescriptions for the first set in linien units.

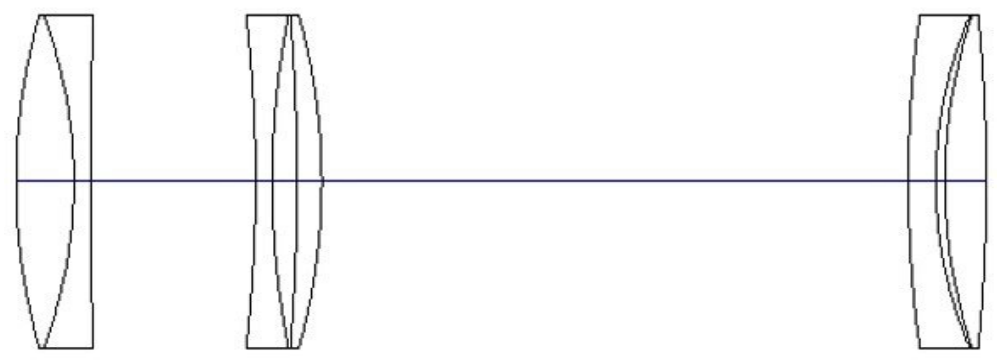

Fig. 1. Modern reproduction of Petzval's drawing showing three doublet lenses

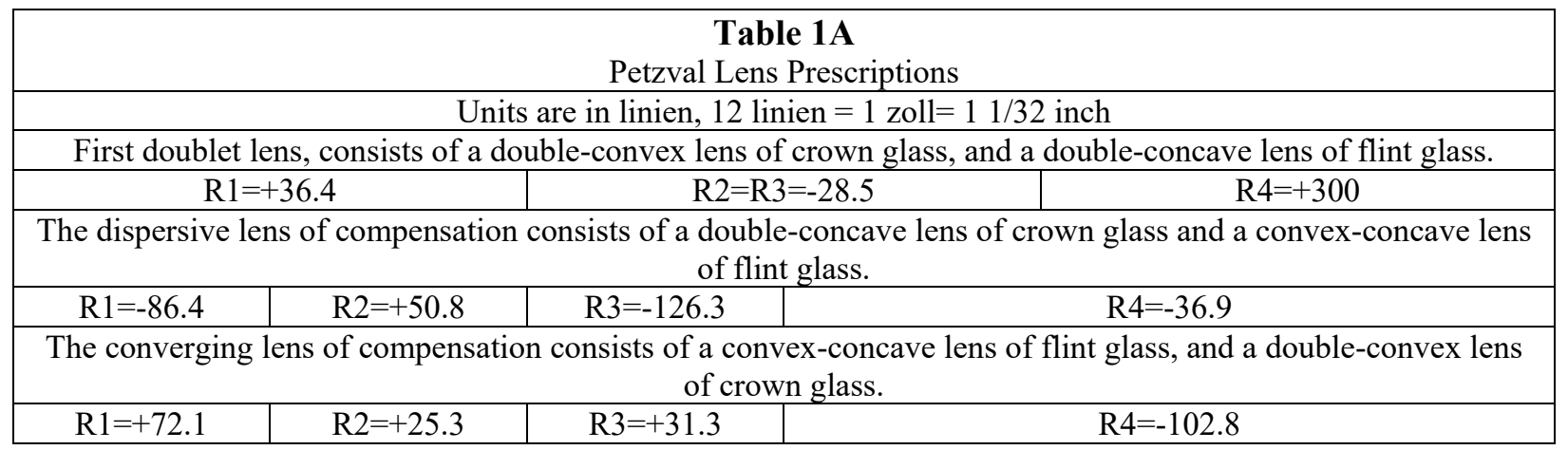

Table 1B provides the prescriptions for the second set of objectives in zoll and linien units. The prescription table provides the radii of curvature and glass types for three doublet lenses. The first and second doublets form the landscape objective lens for views, and the first and third doublets form the objective for portrait photography. No lens thickness or air gaps, indices of refraction, dispersion numbers, nor the position of the aperture stop are given. For the first and second doublets the numerical values in Petzval's lens prescription that are given in zoll units are slightly different from the ones in linien units. Voigtländer writes [3] that Petzval indicated that the numbers marked in pencil (the ones in zoll units and in Table 1B) were the ones to use for making the lens curvatures. A drawing of the three doublets also appears as part of the prescription and is reproduced in Fig. 1 that was drawn with modern lens design software.

A photograph of the original prescription was part of a poster in commemoration of the 200th anniversary of the birth of Petzval [8]. From this photograph one can verify that the notarized copy is in substantial agreement with the original. The drawings, original and copy, show that center and edge thicknesses, and doublet air gaps have been minimized. The negative lens of the third doublet shows a central thickness that is about twice that of the other negative lenses. 


\begin{tabular}{|c|c|c|}
\hline \multicolumn{3}{|c|}{$\begin{array}{c}\text { Table 1B } \\
\text { Petzval Lens Prescriptions }\end{array}$} \\
\hline \multicolumn{3}{|c|}{ Units are in linien, 12 linien $=1$ zoll= $=11 / 32$ inch } \\
\hline \multicolumn{3}{|c|}{ First doublet lens, consists of a double-convex lens of crown glass, and a double-concave lens of flint glass. } \\
\hline $\mathrm{R} 1=+3.0$ zoll & $\mathrm{R} 2=\mathrm{R} 3=-2.37 \mathrm{zoll}$ & $\mathrm{R} 4=+25$ zoll \\
\hline \multicolumn{3}{|c|}{$\begin{array}{c}\text { The dispersive lens of compensation consists of a double-concave lens of crown glass and a convex-concave lens } \\
\text { of flint glass. }\end{array}$} \\
\hline \begin{tabular}{l|l}
$\mathrm{R} 1=-7.11$ zoll & $\mathrm{R} 2=+4.32$ zoll \\
\end{tabular} & $\mathrm{R} 3=-9.03$ zoll & R4=-3.11 zoll \\
\hline \multicolumn{3}{|c|}{$\begin{array}{c}\text { The converging lens of compensation consists of a convex-concave lens of flint glass, and a double-convex lens } \\
\text { of crown glass. }\end{array}$} \\
\hline \begin{tabular}{l|l}
$\mathrm{R} 1=+72.1$ linien & $\mathrm{R} 2=+25.3$ linien \\
\end{tabular} & $\mathrm{R} 3=+31.3$ linien & $\mathrm{R} 4=-102.8$ linien \\
\hline
\end{tabular}

Petzval years later [2] described a new lens that Voigtländer [3] measured and showed to have in proportion of 2 substantially the same radii of curvature as the landscape lens in the original prescription in Table $1 \mathrm{~A}$. The analysis below relies on the prescriptions in Table 1A in linien units.

\section{LENS SPECIFICATIONS}

Petzval provided partial lens prescriptions for two objective lenses. The thick lens reconstruction presented below of Petzval's landscape lens gives a focal length of 13.78 zoll and a relative aperture of F/9.19 as the aperture was 1.5 zoll. In his report of 1857 Petzval indicates that the focal length of the portrait lens is 5.5 zoll and an aperture of 1.5 zoll which results in a relative aperture of F/3.67. In this specification Petzval was aggressive and clearly understood the need for a large relative aperture.

Petzval in his report of 1857 makes the remark that the first doublet in the portrait objective serves as the diaphragm for the second doublet. He also explains "Here it is the frame of the first lens which takes over the role of the diaphragm." This indicates that the aperture stop was at the first doublet, and is consistent with a description of light vignetting of the portrait objective in the same report. Further, in discussing the landscape lens P. F. Voigtländer stated in his letter that no stops were used [3]. Thus the rim of the first cemented doublet served as the aperture stop.

The report of 1843 provides a brief outline of Petzval theory of aberrations in which he describes five third-order aberrations, twelve fifth-order aberrations, and twenty seventh-order aberrations. At the close of his report he mentions the calculations of lens prescriptions for several applications, i.e. telescopes, camera obscuras, microscopes, were all completed with images of the fifth-order, meaning corrected for at least some third-order aberrations. To highlight his own theoretical work Petzval also alluded to the methods of the calculating opticians that used trigonometrical calculations (i.e. real raytracing) for lens improvement, as complicated and slow calculations, resulting in lens systems falling behind expectations and illusory. Later in 1857 in his description of his new lens he states that this lens would reproduce a faultless image of the fifth-order. These descriptions by Petzval indicate that he controlled image quality by calculating third-order aberration coefficients, rather than by real ray tracing.

In his report of 1843 Petzval describes the field curves and how for an object having radial lines and concentric circles the image on a screen becomes distinct for either the radial lines or the concentric circles, depending on the screen position. He explains that the more neatly and distinctly a telescope which has a large field of vision shows this phenomena, the more carefully its objective has been calculated and executed. Further, in his report of 1857 he states that for a lens with a 3 zoll aperture and a focal length of 16 zoll, such as it was in general use in the early period of Daguerreotyping, a 1 zoll aperture diaphragm is best placed at a distance of 3 zoll before the lens. Analysis of this lens shows that the position of the diaphragm (aperture stop) as shown in Fig. 2 makes the medial field curve about flat. He also explains in his report of 1857 that there are eight conditions to satisfy for a camera lens, five for the destruction of spherical aberration, two for the production of achromatism, and one for the position of the focus. Petzval further explains,

"Greater illumination, one of the desired improvements, can only be obtained in two ways - by enlarging the aperture and by diminishing the focal length, both which, however, will result from employing two converging lenses, instead of 
one. These lenses must of course be achromats; and by theory, in order that a good image may be produced, they must be separated from each other by a distance no less than one third of the focal length of the lens near the object."

These descriptions by Petzval indicate that in terms of image quality he set to correct for the chromatic aberrations, spherical and coma aberrations, and to flatten the field. For this he needed two separated doublets with the second one contributing negative coma as to produce negative astigmatism and artificially flatten the field.

By considering the physical dimensions of the early Petzval-Voigtländer conical brass cameras with circular emulsion plates, $150 \mathrm{~mm}$ focal length and $94 \mathrm{~mm}$ plate diameter [7], one can estimate that for the portrait lens the field of view was about $+/-16.5$ degrees. Light vignetting is about $50 \%$ for this field of view.

As per the field of view of the landscape lens A. Martin wrote that, "This combination of lenses was to produce a plane image and large range, and the image was to fill up the whole surface of a normal Daguerrian plate." Taking the size of a full plate to be approximately 6.5 by 8.5 inches the field of view becomes about $+/-21$ degrees. Table 2 provides a summary of the specifications. The focal lengths are taken from the thick lens models presented below.

\begin{tabular}{|c|c|c|}
\hline \multicolumn{3}{|c|}{$\begin{array}{r}\text { Table 2 } \\
\text { Reconstructed Petzval lens }\end{array}$} \\
\hline Specification & Landscape lens & Portrait lens \\
\hline $\begin{array}{l}\text { Aperture stop } \\
\text { location }\end{array}$ & At first doublet & At first doublet \\
\hline $\begin{array}{l}\text { Aperture stop } \\
\text { diameter }\end{array}$ & 1.5 zoll & 1.5 zoll \\
\hline $\mathrm{F} / \#$ & 9.23 & 3.67 \\
\hline Focal length & 13.84 Zoll & 66.02 Zoll \\
\hline Field of view & $+/-21$ degrees & $+/-16.5$ degrees \\
\hline Object distance & $\begin{array}{l}\text { Infinite/ } \\
84 \text { Zoll }\end{array}$ & 84 Zoll \\
\hline Construction & $\begin{array}{c}\text { Two separated } \\
\text { doublets }\end{array}$ & $\begin{array}{c}\text { Two separated } \\
\text { doublets }\end{array}$ \\
\hline $\begin{array}{l}\text { Chromatic } \\
\text { aberration }\end{array}$ & $\begin{array}{l}\text { Individually } \\
\text { corrected at } \\
\text { each doublet }\end{array}$ & $\begin{array}{l}\text { Individually } \\
\text { corrected at } \\
\text { each doublet }\end{array}$ \\
\hline $\begin{array}{l}\text { Spherical } \\
\text { aberration }\end{array}$ & $\begin{array}{l}\text { Individually } \\
\text { corrected at } \\
\text { each doublet }\end{array}$ & $\begin{array}{l}\text { Individually } \\
\text { corrected at } \\
\text { each doublet }\end{array}$ \\
\hline Coma aberration & Corrected & Corrected \\
\hline $\begin{array}{c}\text { Astigmatism } \\
\text { aberration }\end{array}$ & $\begin{array}{c}\text { Negative to } \\
\text { artificially } \\
\text { flatten the field }\end{array}$ & $\begin{array}{c}\text { Negative to } \\
\text { artificially } \\
\text { flatten the field }\end{array}$ \\
\hline Vignetting & Yes & Yes \\
\hline Image quality & $\begin{array}{l}\text { Comparable of } \\
\text { better to } \\
\text { achromatic } \\
\text { landscape lens }\end{array}$ & $\begin{array}{c}\text { Excellent } \\
\text { around the field } \\
\text { center. }\end{array}$ \\
\hline
\end{tabular}

Voigtländer [3] comments that the desire of Prof. Ettingshausen was a better lens for landscapes. This may explain why the landscape lens is given first in Petzval's prescription. Whereby we set the image quality at least comparable or better to the achromatic landscape lens in view of the faster photographic speed. As per the portrait lens its excellent image quality around the field center speaks for this specification which requires an aplanatic or nearly so correction. 


\section{ACHROMATIC LANDSCAPE LENS AS PRIOR ART}

Petzval had mentioned the achromatic doublet used in the early Daguerreotype cameras as shown in Fig. 2, and also mentioned that the diaphragm is best placed at a distance of 3 zolls from the lens [1]. The lens in Fig, 2 is the first doublet specified by Petzval in Table 1 but has been reversed and scaled by a factor of two to make it 3 zoll in diameter; lens thicknesses and index of refraction have been added, the aperture stop is 1 zoll in diameter and 3 zoll in front. The object distance was set to 84 zoll in consideration of portrait photography. The field curves show a nearly flat medial surface as the ratio of astigmatism $\mathrm{W}_{222}$ to Petzval field curvature $\mathrm{W}_{220 \mathrm{p}}$ is -1.04 . Within fourth-order aberration theory a ratio of -1 would indicate a flat medial surface, and a ratio of $-2 / 3$ would indicate a flat tangential surface. If the lens thicknesses are set to zero, for a thin lens analysis, the ratio $\mathrm{W}_{222} / \mathrm{W}_{220 \mathrm{P}}$ becomes -0.79 . Petzval had been asked to understand the shape of lenses used in photography and described astigmatism aberration in his report of 1843 . No doubt that he analyzed how the achromatic landscape lens works. Thus in his design for the landscape and portrait lenses of Tables $1 \mathrm{~A}$ and $1 \mathrm{~B}$ he artificially flattened the field.

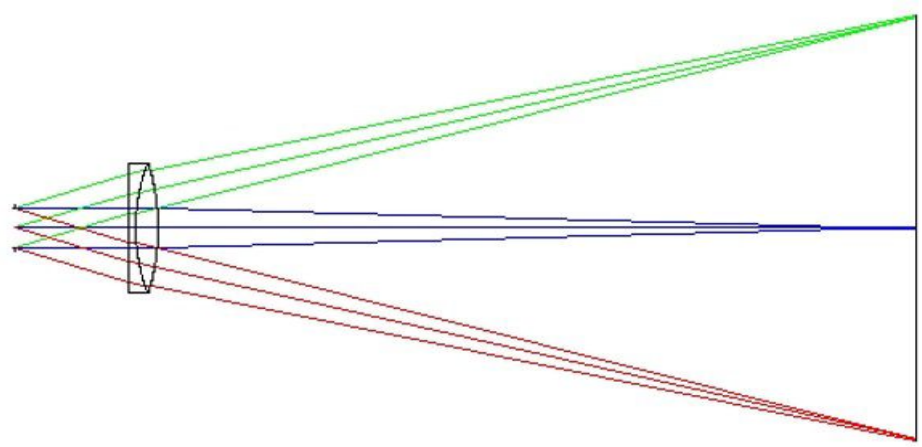

Fig. 2. Landscape achromatic lens with aperture stop in front.

\section{FIRST-ORDER DESIGN}

In describing light vignetting for a lens twice the size of the original portrait objective, Petzval [2] set the focal length of the first lens to 16 zoll, the focal length of the second lens to 24 zoll, the lens separation to $51 / 3$ zoll, and an aperture of 3 zoll. This lens combination gives a focal length of 11 zoll when the lens separation is set to 5.1 zoll. By scaling by a factor of $1 / 2$ one obtains the aperture and focal length of the original objective for portraits, these being $1 \frac{1}{2}$ and $5 \frac{1}{2}$ zoll respectively, for a speed of $\mathrm{f} / 3.67$. The focal length of the first lens is 8 zoll, the focal length of the second lens is 12 zoll, and the lens separation is 2.55 zoll. This lens is shown as a thin lens combination in Fig. 3 and represents Petzval's firstorder design concept. The stop is placed at the first lens after Petzval comment, "It will be at once seen that here the setting of the first lens plays the part of the former diaphragm..." [2].

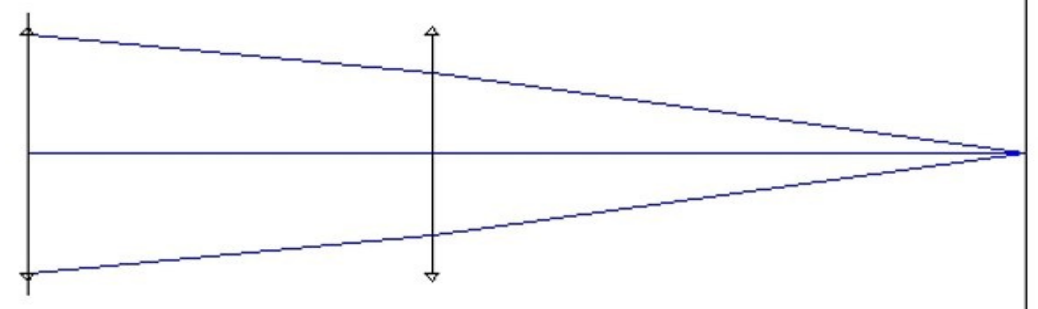

Fig. 3. Portrait objective, first-order model. 
Years later Petzval in his 1857 report mentions that his new lens had a focal length of 26 zoll. This new lens was substantially a scaled version (by a factor of 2) of the original landscape objective. One possibility for a first-order model that Petzval could have used for the landscape objective is a first doublet with a focal length of 8 zoll, a second doublet with a focal length of -16 zoll, and separation of 1 zoll. These values give an effective focal length of 14.22 zoll. A. Martin [3] also commented that the aperture of the landscape lens was 1.5 zoll which results in a speed of f/9.48. A second possibility is to have the second doublet with a focal length of -18 zoll and a separation of 1 zoll which give an effective focal length of 13.09 zoll and a speed of $\mathrm{f} / 8.73$.

Voigtländer manufactured the landscape objective and called it "Orthoscopic Lens." A description of this lens appeared in Photographic Notes [9] of 1858. The focal length given for the front doublet is 40 centimeters, for the rear doublet is 90 centimeters, a separation of 4 centimeters, and an effective focal length of 63 centimeters. Scaling these values give a focal length of 8 zoll for the front doublet, a focal length of -18 zoll for the rear doublet, a separation of 9.6 linien, and an effective focal length of 12.6 zoll. These values reflect the understanding Voigtländer had of Petzval's landscape design.

\section{THIN LENS ACHROMATIC SOLUTION}

The secret of the thin achromatic doublet is that the ratio of the optical powers of the individual lenses must be equal to the negative of the ratio of the glasses v-numbers. The original Petzval prescription does not provide indices of refraction or v-numbers. Voigtländer [3] provided to Petzval the index of refraction and dispersion numbers of the glasses. Eder [4] wrote that the indices of refraction were 1.517 and 1.575 for the crown and flint glasses respectively; Eder does not mention where he obtained these values from. However, Eder's values provide correction for spherical aberration for Petzval's front doublet when it is analyzed as a thin lens. Eder also provides the diameter of the front doublet as 18 linien, and the diameter of the rear doublet as 19 linien. When thickness is added, however, there is a better match to a doublet with a focal length of 8 zoll but spherical aberration is not quite corrected.

\begin{tabular}{|c|c|c|c|}
\hline \multicolumn{5}{|c|}{ Table 3 } \\
\hline & Ratios of focal lengths of doublet elements. \\
\hline As thin lenses & -0.6830 & Doublet two f1/f2 & Doublet three $\mathrm{f} 1 / \mathrm{f} 2$ \\
\hline As thick lenses & -0.6966 & -0.6825 & -0.6847 \\
\hline
\end{tabular}

By using Eder's indices of refraction the focal lengths of the doublet lens elements can be calculated. Table 3 provides the ratio of the focal lengths of the individual lenses of the three Petzval doublets when they are treated as thin lenses and then as thick lenses. Because for the thin lens case the ratio of the focal lengths is more uniform, the comparison indicates that Petzval designed the doublets as thin lenses. Further, the fact that the first doublet, as a thin doublet, is well corrected for spherical aberration and chromatic change of focus also supports the use of a thin lens model.

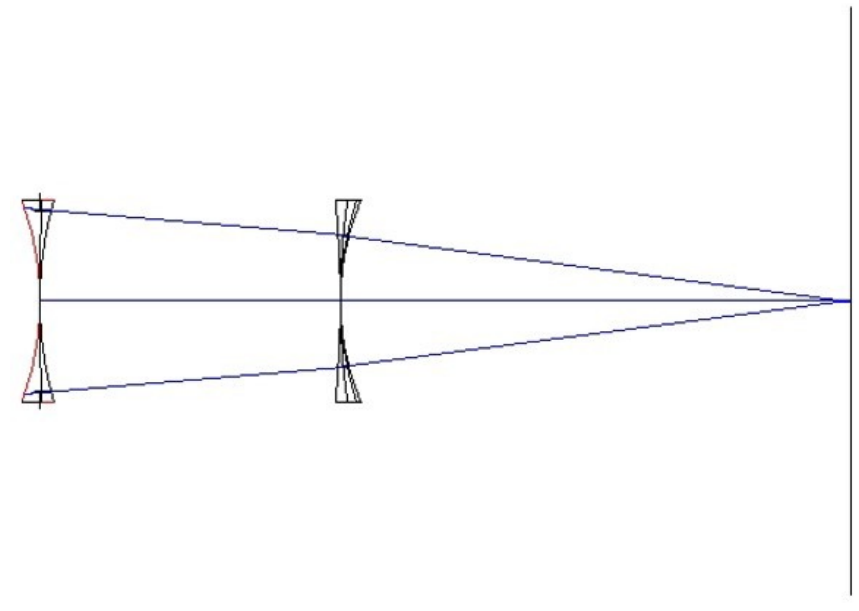

Fig. 4. Portrait objective thin lens solution. 
Based on matching the first-order model focal lengths, and/or on a different correction for spherical aberration (i.e. for the whole objective), it is possible to come up with other slightly different values for the indices of refraction. However, in this study we use the indices provided by J. Eder. As per the v-values we take them to be 64.00 and 43.74 for the crown and flint glasses which give a ratio of 0.6834 and thus provide correction for chromatic aberrations.

\section{THIRD-ORDER THIN LENS DESIGN}

In his original prescription Petzval referred to the second doublet as of compensation. He knew that depending on the aperture stop position, the achromatic landscape lens could produce positive or negative astigmatism. He envisioned the first doublet in the portrait objective serving as the aperture stop for the second doublet, and sought to compensate coma and astigmatism aberration of the first doublet with the second doublet, while increasing the photographic speed. Chromatic aberrations and spherical aberration were corrected individually at each doublet. The rear doublet was air spaced as to gain a degree of freedom to introduce at will negative coma, and then negative astigmatism in view of a remote aperture stop.

When the object distance is set to 84 zoll, and the distances between doublets are set to 11.75 linien for the landscape lens and 30 linien for the portrait lens third-order coma aberration is corrected. Then it is found that the resulting focal lengths are 14.52 zoll and 5.57 zoll respectively. Thus correcting third-order coma nearly results in the focal length of 5.5 zoll given by Petzval for the portrait lens. The resulting ratios of astigmatism to Petzval field curvature aberration $\mathrm{W}_{222} / \mathrm{W}_{220 \mathrm{P}}$ for the landscape and portrait lenses are -0.79 and -0.81 respectively. These ratios are similar to the same ratio for the thin landscape achromatic lens discussed above, and so there is consistency. The thin lens design for the portrait objective is shown in Fig. 4.

If the distance between doublets of the portrait objective is set to 32 linien, or $1 / 3$ the focal length as Petzval remarked [2], then the ratio $\mathrm{W}_{222} / \mathrm{W}_{220 \mathrm{P}}$ becomes -0.94 indicating nearly a flat medial surface correction. Petzval statement that the distance between doublets is at least $1 / 3$ of the focal length of the first doublet lens requires knowledge about the calculation of coma aberration and the generation of negative astigmatism for flattening the field. In the Appendix we show that correcting third-order coma and having a flat medial astigmatic field curve, requires indeed a separation of the doublets of about $1 / 3$ the focal length of the front doublet.

Years later, Petzval in his report of 1857 stated that his new lens was designed to reproduce maps with a 1:5 scale, and that the best way to take a group photograph is to place people on a circle of 7' radius (hence the 84 zoll used in the specifications in this paper). As mentioned before, the Petzval new lens was measured by Voigtländer [3] and is substantially in proportion the same as in the original prescription. Some differences are the lower F/\# and the position of the aperture stop at the second doublet to render an unvignetted field of view, and the distance between doublets which is given by Petzval to be slightly less than $1 / 2$ zoll [2].

It is arguable that Petzval set the object distance to 84 zoll for the landscape lens as it was intended for landscapes. If the object distance is set to infinity and correction for third-order coma is retained, then the ratio $\mathrm{W}_{222} / \mathrm{W}_{220 \mathrm{P}}$ becomes 0.34. This ratio would indicate that a different correction to artificially flatten the field was given to the landscape and portrait lenses. This difference in correction is difficult to explain and it is unlikely that Petzval would have not best artificially flattened the field. A. Martin [3] had written that the objective for views was to produce a plane image. For an object at infinity and a doublet separation of 13 linien the landscape thin lens model provides a ratio $\mathrm{W}_{222} / \mathrm{W}_{220 \mathrm{P}}$ of 0.68 . This ratio within third-order theory represents nearly a flat tangential field surface. However, coma aberration $\mathrm{W}_{131}$, becomes 4.07 waves at a full semi field of $21^{\circ}$.

When the doublet separation in the Petzval objectives become smaller, less negative astigmatism is contributed by the second doublet and less artificially flattened the field becomes. This is a sensitive effect and Petzval must have been aware of it. For his new lens Petzval also wrote [3] that the second doublet is placed at a distance of one twelfth to one sixteenth of the focal length of the first doublet according to purpose the lens is to serve for. Petzval most likely aimed to achieve the same artificial field flattening that he found best when analyzing a landscape achromatic doublet. 


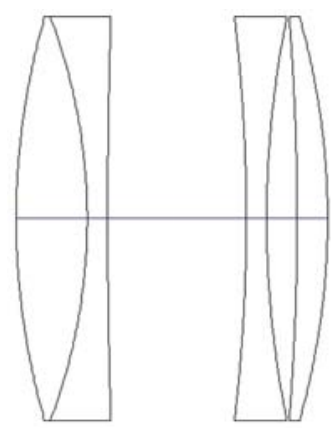

Fig. 5. Petzval landscape lens with thicknesses added.

\section{THICK LENS DESIGN}

Following Petzval drawings, element thicknesses for the three doublets were set to 3.5 and 1 linien for the first doublet, 1, 1.5, and 1.5 linien for the second, and 2, 0.55 and 2.5 for the third doublet. For an object distance of 84 zoll and to correct for third-order coma the distance between the thick doublets needed to be changed to 6.83 linien and 23.93 linien for the landscape and portrait objectives respectively. The ratios of astigmatism to Petzval field curvature $\mathrm{W}_{222} / \mathrm{W}_{220 \mathrm{P}}$ then become -0.92 and -0.44 respectively. If the object is at infinity for the landscape objective, and the distance between doublets is set to 6.15 linien to correct third-order coma, then the ratio $\mathrm{W}_{222} / \mathrm{W}_{220 \mathrm{P}}$ becomes -0.54 .

Figures 5 and 6 show the cross sections of the objective lenses when thicknesses are added. The distance between doublets in the landscape lens of 6.83 linien (or 6.15) is not consistent with the larger distance of 9 linien between doublets in Petzval's reproduced drawing of Fig. 1. The distance between doublets in the portrait lens of 23.93 linien, is at odds with Petzval's remark of a distance of at least 1/3 the focal length of the first doublet, or 32 linien. Further, the rations $\mathrm{W}_{222} / \mathrm{W}_{220 \mathrm{P}}$ indicate that a different correction would have given to artificially flattening the field. The ratio $\mathrm{W}_{222} / \mathrm{W}_{220 \mathrm{P}}=-0.44$ is small for properly flattening the field. Therefore, it is not supported that Petzval performed a thick element third-order design.

If some coma aberration is allowed then a case for a thick design can be made. However, it is hard to support that Petzval would have allowed coma to be present. The level of aberration correction Petzval considered necessary is suggested by changing the shape of the front doublet to convex-plano, rather than slightly a meniscus shaped lens. This change results in a change of about -3 waves of spherical aberration and -11 waves of coma aberration. These aberration values were most likely objectionable to Petzval.

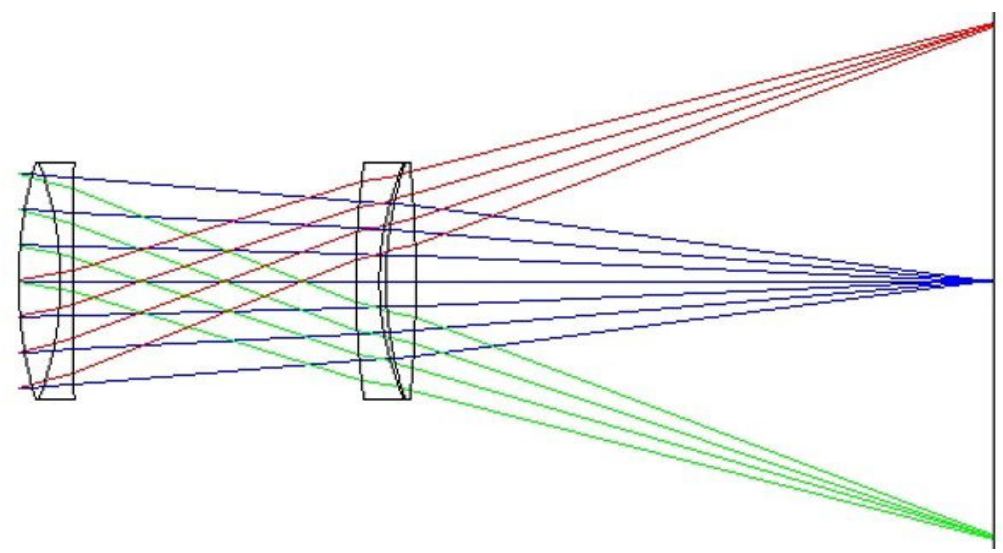

Fig. 6. Petzval portrait lens with lens thicknesses added. The light rays are for the on axis, and $+/-16.5$ degrees field of view object positions. 
Right after the fabrication of the first portrait lens Voigtländer [3] found that increasing the airspace in the rear doublet would improve the lens. Voigtländer wrote: "Prof. Petzval and I finding that, by this ring (i.e. a spacer) we could compensate for some errors, which must have taken place in the calculation." Thus for the portrait objective the distance between doublets and rear doublet airspace were best set by trial and error. Voigtländer [3] comments that Petzval examined the lenses after they were fabricated and found them not as perfect as he wished. It was at the urging of Voigtländer that the objectives were practically tried. Anton Martin took the task of testing the objectives by taking photographs. The landscape objective was laid aside. Later Petzval [2] in a twice as large version with the stop at the second doublet, presented it as his new lens $[2,6]$.

\section{FOCAL LENGTHS}

The focal lengths of the lenses for the thin and the thick lens models are given in Table 4 for both the portrait objective and the landscape objective.

\begin{tabular}{|c|c|c|c|c|c|c|c|}
\hline \multicolumn{8}{|c|}{$\begin{array}{c}\text { Table } \mathbf{4} \\
\text { Lens focal lengths in linien for the portrait and lan }\end{array}$} \\
\hline $\begin{array}{c}\lambda=0.587 \\
\mathrm{~nm}\end{array}$ & $\begin{array}{l}\text { First } \\
\text { lens }\end{array}$ & $\begin{array}{l}\text { Second } \\
\text { lens }\end{array}$ & $\begin{array}{c}\text { First } \\
\& \\
\text { Second }\end{array}$ & $\begin{array}{l}\text { Third } \\
\text { lens }\end{array}$ & $\begin{array}{c}\text { Fourth } \\
\text { lens }\end{array}$ & $\begin{array}{c}\text { Third } \\
\& \\
\text { Fourth }\end{array}$ & EFL \\
\hline $\begin{array}{l}\text { Firs-order } \\
\text { model }\end{array}$ & & & 96 & & & 144 & 66 \\
\hline $\begin{array}{l}\text { Thin lens } \\
\text { portrait }\end{array}$ & 30.91 & -45.26 & 97.54 & -67.78 & 46.41 & 147.17 & 66.86 \\
\hline $\begin{array}{c}\text { Thick lens } \\
\text { portrait }\end{array}$ & 31.49 & -45.21 & 96.19 & -68.86 & 46.71 & 143.63 & 66.02 \\
\hline & & & & & & & \\
\hline $\begin{array}{l}\text { First-order } \\
\text { model }\end{array}$ & & & 96 & & & $-192 /-216$ & $\begin{array}{l}170.67 \\
/ 157.09\end{array}$ \\
\hline $\begin{array}{l}\text { Thin lens } \\
\text { landscape }\end{array}$ & 30.91 & -45.26 & 97.54 & -61.88 & 90.66 & $\begin{array}{l}-194.9 \\
\end{array}$ & 174.26 \\
\hline $\begin{array}{l}\text { Thick lens } \\
\text { landscape }\end{array}$ & 31.49 & -45.21 & 96.19 & -61.72 & 89.93 & -219.8 & 166.17 \\
\hline
\end{tabular}

\section{SPHERICAL ABERRATION}

Table 5 provides the fourth-order wave coefficient, sixth-order, and total optical path difference (OPD) for spherical aberration for the thin and thick Petzval objectives. Fourth-order spherical aberration of the thin first doublet is well corrected to 0.24 waves, but not as much for the thick first doublet which has 0.98 waves.

The total aberration for the thin portrait and landscape objectives is 0.69 and 0.11 waves. While the total aberration for the thick portrait and landscape objectives is 1.68 and 2.14 waves. These differences further support a thin lens model, first-order ray tracing, and the use of aberration coefficients for the calculations, rather than using real ray tracing.

\begin{tabular}{|c|c|c|c|c|c|c|}
\hline \multicolumn{7}{|c|}{$\begin{array}{c}\text { Table 5 } \\
\text { Spherical aberration of the thin and thick Petzval objectives. } \\
\text { Object distance } 84 \text { zoll. }\end{array}$} \\
\hline $\begin{array}{c}\lambda=0.587 \\
\mathrm{~nm}\end{array}$ & $\begin{array}{c}\text { Thin } \\
\text { Portrait } \\
\text { first } \\
\text { doublet }\end{array}$ & $\begin{array}{c}\text { Thin } \\
\text { Portrait } \\
\text { complete } \\
\text { objective }\end{array}$ & $\begin{array}{c}\text { Thick } \\
\text { Portrait } \\
\text { first } \\
\text { doublet }\end{array}$ & $\begin{array}{c}\text { Thick } \\
\text { Portrait } \\
\text { complete } \\
\text { objective }\end{array}$ & $\begin{array}{c}\text { Thin } \\
\text { Landscape } \\
\text { complete } \\
\text { objective }\end{array}$ & $\begin{array}{c}\text { Thick } \\
\text { Landscape complete } \\
\text { objective }\end{array}$ \\
\hline $\mathrm{W}_{040}$ & $0.24 \lambda$ & $1.45 \lambda$ & $0.98 \lambda$ & $2.28 \lambda$ & $0.94 \lambda$ & $2.61 \lambda$ \\
\hline $\mathrm{W}_{060}$ & $-0.57 \lambda$ & $-0.68 \lambda$ & $-0.49 \lambda$ & $-0.58 \lambda$ & $-0.71 \lambda$ & $-0.55 \lambda$ \\
\hline OPD & $-0.43 \lambda$ & $0.69 \lambda$ & $0.46 \lambda$ & $1.68 \lambda$ & $0.11 \lambda$ & $1.98 \lambda$ \\
\hline
\end{tabular}


Note that to compute aberration coefficients the objective data in linien were entered in a lens design program using millimeters as the units. Therefore all aberration coefficients in this paper correspond to objectives in millimeters units, or about 2.18 times smaller than their actual size when the zoll is taken equal to $11 / 32$ of an inch.

\section{ABERRATION COEFFICIENTS}

It was found in practice that separating the lens elements of the rear doublet in the portrait objective improved image quality. Table 6 presents the fourth and sixth-order wave aberration coefficients [10] for the thick portrait objective model. Table 7 presents the coefficients when the separation between elements of the rear doublet is increased by 1.5 linien.

The sixth-order coma $\mathrm{W}_{331}$ and astigmatism $\mathrm{W}_{422}$ of the thick model are significant and left unbalanced. A fifth-order design would have considered these aberrations.

The effects of the increased element separation are 1) reduction of sixth-order coma $\mathrm{W}_{331}$, for a better balance with fourth-order coma $\mathrm{W}_{131}, 2$ ) reduction of fourth-order $\mathrm{W}_{222}$ and sixth-order $\mathrm{W}_{422}$ astigmatism, and 3) reduction of distortion $\mathrm{W}_{311}$ and $\mathrm{W}_{511}$.

This aberration analysis and the fact that the portrait objective was adjusted for better performance do not support that Petzval used higher than third-order aberration coefficients, or real ray tracing, to perform his designs.

\begin{tabular}{|c|c|c|c|c|}
\hline \multicolumn{5}{|c|}{$\begin{array}{l}\text { Table } 6 \\
\text { Fourth and sixth-order aberration coefficients in waves for the thick lens portrait model. } \\
\text { Object distance } 84 \text { zoll. } \\
\lambda=0.587 \mathrm{~nm}\end{array}$} \\
\hline $\mathrm{W}_{040}$ & $\mathrm{~W}_{131}$ & $\mathrm{~W}_{222}$ & $\mathrm{~W}_{220}$ & $\mathrm{~W}_{311}$ \\
\hline 2.28 & 0.0 & -16.4 & 28.49 & -33.46 \\
\hline $\mathrm{W}_{240}$ & $\mathrm{~W}_{331}$ & $\mathrm{~W}_{422}$ & $\mathrm{~W}_{420}$ & $\mathrm{~W}_{511}$ \\
\hline-1.83 & -10.49 & -38.52 & -11.93 & -44.37 \\
\hline $\mathrm{W}_{060}$ & $\mathrm{~W}_{151}$ & $\mathrm{~W}_{242}$ & $\mathrm{~W}_{333}$ & \\
\hline-0.58 & 0.72 & -3.55 & -7.19 & \\
\hline
\end{tabular}

\begin{tabular}{|c|c|c|c|c|}
\hline Fourth & er aberr & $\begin{array}{l}\text { Table } \\
\text { cients it } \\
\text { distance } \\
=0.587 \text {. } \\
\text { f the se }\end{array}$ & t set to & it model. \\
\hline $\mathrm{W}_{040}$ & $\mathrm{~W}_{131}$ & $\mathrm{~W}_{222}$ & $\mathrm{~W}_{220}$ & $\mathrm{~W}_{311}$ \\
\hline 2.34 & 3.20 & -10.10 & 31.63 & 18.60 \\
\hline $\mathrm{W}_{240}$ & $\mathrm{~W}_{331}$ & $\mathrm{~W}_{422}$ & $\mathrm{~W}_{420}$ & $\mathrm{~W}_{511}$ \\
\hline-1.64 & -8.11 & -25.46 & -9.27 & -24.56 \\
\hline $\mathrm{W}_{060}$ & $\mathrm{~W}_{151}$ & $\mathrm{~W}_{242}$ & $\mathrm{~W}_{333}$ & \\
\hline-0.58 & 0.79 & -2.75 & -5.38 & \\
\hline
\end{tabular}

For the Landscape objective the fourth and sixth-order aberration coefficients are given in Table 8. The object was set at infinity and the separation between doublets was set to 6.15 linien which corrects third-order coma. The focal length then is 13.92 zoll. 


\begin{tabular}{|c|c|c|c|c|}
\hline \multicolumn{5}{|c|}{ 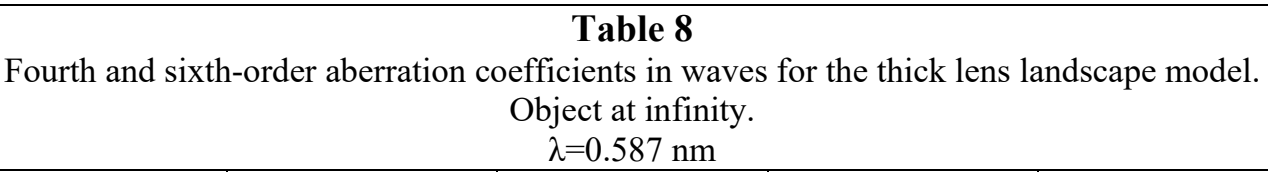 } \\
\hline $\mathrm{W}_{040}$ & $\mathrm{~W}_{131}$ & $\mathrm{~W}_{222}$ & $\mathrm{~W}_{220}$ & $\mathrm{~W}_{311}$ \\
\hline 2.55 & 0.01 & -10.02 & 13.49 & -93.02 \\
\hline $\mathrm{W}_{240}$ & $\mathrm{~W}_{331}$ & $\mathrm{~W}_{422}$ & $\mathrm{~W}_{420}$ & $\mathrm{~W}_{511}$ \\
\hline-0.04 & 3.71 & -10.33 & -5.90 & 4.00 \\
\hline $\mathrm{W}_{060}$ & $\mathrm{~W}_{151}$ & $\mathrm{~W}_{242}$ & $\mathrm{~W}_{333}$ & \\
\hline-0.55 & -0.31 & 2.87 & 3.98 & \\
\hline
\end{tabular}

At full field, field curvature aberration $\mathrm{W}_{220}+\mathrm{W}_{420}$ is 7.59 waves, and astigmatism aberration $\mathrm{W}_{222}+\mathrm{W}_{422}$ is -20.35 waves, indicating a nearly flat, slightly outward curving, medial field curve. Near the field center third-order field aberrations dominate and the ratio $\mathrm{W}_{222} / \mathrm{W}_{220 \mathrm{P}}$ is -0.54 indicating a slightly inward curving tangential field curve. Spherical aberration and coma are not significant and as such the overall aberrations show a balanced design. Petzval was well aware of aberration balancing as he discusses it in his 1843 report. However, a separation of 6.15 linien is not consistent with the distance between doublets in Petzval original drawing of about 9 linien, or with the doublet separation of 9.6 linien in the Voigtländer orthoscopic lens. For a separation of 9 linien there is a residual of 6.7 waves of third-order coma $\mathrm{W}_{131}$, and a residual of 1.94 waves of sagittal field curvature $\mathrm{W}_{220}+\mathrm{W}_{420}$, or nearly flat, which do not indicate a best balanced design.

\section{PRESCRIPTION ADJUSTMENT}

As mentioned earlier, Petzval provided two sets of prescriptions reproduced in this paper separately in Tables $1 \mathrm{~A}$ and 1B. The radii of curvature in Table 1A appear to be written in ink in the original prescription [8]. The radii of curvature in Table 1B for the first and second doublets are given in zoll units and were written in pencil [3]. Petzval must have written the radii in pencil sometime later after he wrote the prescription in ink.

For the first doublet the change of radii from Table 1A to Table 1B for the first surface is 36.4-36.0=0.4 linien, and the change of radius of the second surface is $28.5-28.44=0.06$ linien. These changes do not substantially affect the aberrations but make the focal length to become 96.1 linien, which is nearly the 96 linien of the first-order model.

For the second doublet the radius of the third surface changes from -126.3 linien to -108.36 linien which is a major change. This third surface contributes very little spherical aberration or coma, and contributes astigmatism, field curvature and distortion. The fourth and last surface contributes, in addition to other aberrations, spherical and coma aberration. Thus Petzval chose to change the radius of the third surface as to maintain the objective aplanatic, and to adjust the amount of field flattening or distortion aberration.

\section{REAL RAY OPTIMIZED DESIGN}

The earliest formulae for real ray tracing for lens design likely come from Georg Simon Klügel [11]. Accurate ray tracing for lens design was possible after the precise determination of indices of refraction by Joseph Fraunhofer, around 1815 [12]. Improved formulae for trigonometrical ray tracing were developed much later by L. von Seidel in 1866, including perhaps for the first time the trace of skew rays $[13,14]$. Tracing skew rays would have been necessary for the computation of astigmatism.

Using Petzval prescription, a real ray optimized portrait lens would be close to the thick lens portrait model. There are a number of arguments that do not support that Petzval used real ray tracing. Some arguments are:

- His two criticisms of the calculating opticians in his 1843 report and his repetitive highlighting of aberration theory.

- His remark in his 1843 report that he had calculated 15 lens combinations with images of the fifth-order (meaning a third-order correction or several third-order aberrations corrected). 
- The distance in the prescription drawing between doublets of the landscape objective is consistent with the distance of the thin lens solution, but it is at odds with a thick lens, real ray optimization.

- That the distance between doublets in the portrait objective is at odds with Petzval's remark of at least $1 / 3$ the focal length of the first doublet. Further, this statement reflects a third-order calculation.

- That as late as 1857 Petzval expressly remarked that his new lens was corrected to an image of the fifth-order.

- The correction of chromatic change of focus using a thin lens model.

- The correction of spherical aberration using a thin lens model and aberration coefficients.

\section{OTHER CONSIDERATIONS}

The main sources of information used for this paper are the reports that Petzval wrote, and Voigtländer's letter which contains the statement made by A. Martin. One must consider that except for Petzval's report of 1843 all other information is from 1857-58 or later. A next best source of information is Joseph Eder who actually met Petzval but who was born in 1855, much later to the facts. Some letters from Petzval were translated into the English language by P. Pretsch and published in Photographic Notes. The opinion that Petzval did not use real ray tracing has been also previously expressed $[15,16]$.

Petzval in his 1843 report explains that the first practical result of his dioptric theory was the portrait objective of 1840. He writes that this first result was the motive for which Arch Duke Ludwig provided to him the help of the K\&K Bombardier Corps. Later in 1903 L. Ermenyi [17] wrote that before the end of 1840 the portrait lens became vividly discussed in Vienna and that the imperial court showed such interest that Arch Duke Ludwig provided help. According to this, and contrary to common belief, Petzval did not have calculation help from the K\&K Bombardier Corps to design his famous portrait lens. The Bombardier Corps helped Petzval to calculate the 15 tables (lens prescriptions) for Telescopes, cameras obscuras, and microscopes he wrote about at the close of his report.

Petzval at the close of his 1843 report writes that 15 different lens combinations were calculated with images of the $5^{\text {th }}$ order; this is, the $3^{\text {rd }}$ order was corrected. He also adds, "Calculations for combinations of lenses for images of higher orders have been already initiated." This statement suggests that Petzval tackled fifth-order coefficients much later than 1840 and further supports that the portrait objective was calculated with only third-order aberration coefficients.

A recent website [18] provides a clearer photograph of the original prescription. This photograph shows that in addition to drawing the doublets, Petzval also drew with significant detail mechanical structures holding the doublets, this is the lens barrel in three parts. The drawing shows an aperture stop in the structure holding the third doublet with an opening of about half the diameter of the doublets. When assembled the aperture would be located about half way between the doublets of the portrait objective making the objective to have an $\mathrm{F}$ number of about $\mathrm{F} / 6.1$. This suggest that originally Petzval designed the portrait objective with a slower optical speed and that due to the practical circumstances it was tested without the drawn aperture stop. Petzval's drawing also shows a deep (about 12 linien in length) light hood in front of the first doublet, which would cause light vignetting.

By relying on Petzval's drawing, and assembling the portrait objective symmetrically about the drawn aperture stop, the doublet spacing would be about 24 linien. This separation corrects third-order coma and decreases the negative astigmatism for a better artificially flattening of the field when higher order astigmatism is considered. In this case Petzval's statement of 1857 about the separation of the doublets would need to be neglected. For the landscape objective Petzval's drawing shows that the first and second doublets have a separation restricted to be at least 9 linien, which for an object at infinity does not correct for third-order coma.

It appears that Prof. Ettingshausen returned to Vienna in October of 1839 and that the first objective was manufactured by May of 1840. If so Petzval might have developed his theory and designed the objectives in a few months, say three to six. Indeed, Petzval at the beginning of his 1843 report states, "Being thoroughly occupied with this subject during the winter of $1840 \ldots$," and "The first practical result was the objective that was used to make portraits, which was exhibited in the summer of $1840 \ldots "$ 
This paper addresses how the Petzval portrait lens in the original prescription was designed. Modifications and improvements such as separating the lens elements in the rear doublet, decreasing the distance between doublets, or locating the aperture stop halfway between doublets came later.

\section{CONCLUSION}

Petzval's reports of 1843 and 1857 are truly an overview of the state of the art in lens design at that time. It is remarkable that Petzval, then 33 years old, in a matter of a few months was able to figure out the basics of first-order design, aberration theory, calculate aberration coefficients, make illumination considerations, and perform successful lens design. In addition of being scientifically excellent, Petzval appears to have been socially charismatic and received the support of leading Austrian personalities.

This paper poses that Petzval, Voigtländer and Martin left enough information to understand how Petzval designed his famous portrait lens. In fact, we show that Petzval followed what it is taught in introductory lens design courses. This is first-order layout, correction of chromatic aberration using doublets, correction of spherical aberration and coma, and artificially flattening the field of view. From Voigtländer's comments one gleans that Petzval had no idea how good his design would turn out to be. It was Voigtländer who urged a practical test. Eder [5] writes that the commercial success of the Petzval portrait lens was immediate and extraordinary, and that it spread with unexpected rapidity.

\section{REFERENCES}

[1] Joseph Petzval, "Bericht über die Ergebnisse einiger dioptrischen Untersuchungen," Verlag von Conrad Adolph Hartleben, Pesth, 1943.

[2] Joseph Petzval, "Bericht über dioptrische Untersuchun," Wien, Sitz. Ber. XXVI., pp. 33-90, 1857. A partial translation into the English language is given by: Joseph Petzval, , "On the Camera Obscura," The London, Edinburgh and Dublin Philosophical Magazine and Journal of Science, Phil. Mag., S. 4. Vol. 17. No. 111, pp. 1-15, Jan 1859.

[3] P. W. F. Voigtländer, "Voigtländer vs. Petzval," Communication from M. Voigtländer to the Editor of Photographic Notes, Journal of the Photographic Society of Scotland and the Manchester Photographic Society, Ed. Thomas Sutton, $p$ 292-302, Dec. $15^{\text {th }}$, 1858. See also: [Akademiker Prof. Dr. Petzval, beleuchtet von Voigtländer], Drud und Berlag von Friedrich Biemeg und Gobn, Braunschweig 1859.

[4] Josef Maria Eder, [Ausfuhrliches Handbuch der Photographie], Halle a. S., Druck und Verlag von Wilhelm Knapp, p.115, 1899.

[5] Josef Maria Eder, [History of Photography], Dover, New York, p. 312, 1978.

[6] Paul Pretsch, "Prof. Petzval's New Lens," Photographic Notes, May 15"th $118-121,1858$.

[7] R. Kingslake, "Petzval's Lens and Camera," Image, p. 60-61, Dec. 1953.

[8] NÁRODNÁ BANKA SLOVENSKA, http://www.nbs.sk/_img/Documents/MENA/PMINCE/pm63a.pdf, May 2017.

[9] Thomas Sutton, “Analysis of the Orthoscopic Lens," Photographic Notes, April 15 ${ }^{\text {th }}$, p. 99-103, 1858.

[10] J. Sasian [Introduction to Aberrations in Optical Imaging Systems], Cambridge University Press, Cambridge 2013.

[11] Georg Simon Klügel, [Analytische Dioptrik], Leipzig, 1778.

[12] Joseph Fraunhofer, "Brechungs-und Farbenzerstrreuungs-Vermogens verschiedener Glasarten," Denkschriften, Akademie der Wissenschaften, Zu Munchen, Band V, p. 193-226, 1817.

[13] L. Von Seidel, "Trigonometrische Formeln fur den allgemeinen Fall der Brchung des Lichtes an centrirten," Flachen: 57, 67, 81, Munch, Sitzungsber. 2 (1866), p. 263-283.

[14] Adolph Steinheil and Ernest Voit, [Applied Optics, The computation of Optical Systems], being the Hanbuch der Angewandten Optic. Blackie and Son Limited, London 1918.

[15] M. von Rohr, [Theorie und Geschichte des Photographischen Objektivs], p. 267, Die Begrenzung der Strahlen, Verlag Von Julius Springer, Berlin, 1899.

[16] Andrew Rakich and Raymond Wilson, "Evidence supporting the primacy of Joseph Petzval in the discovery of aberration coefficients and their application to lens design," Proc. SPIE 6668, Novel Optical Systems Design and Optimization X, 66680B (25 September 2007); doi: 10.1117/12.732666.

[17] L. Ermenyi [Dr. Josef Petzvals Leben und Verdienste], Halle a. S., Verlag von Wilhelm Knapp, p. 25, 1903.

[18] http://www.oldphotographiclenses.com/petzval2.html, Corrado D'Agostini, July 2017. 


\section{APPENDIX}

In this Appendix we provide a calculation for the doublet separation to have a flat medial field curve. This is consistent with Petzval's statement that it is necessary to separate the doublets $1 / 3$ the focal length of the front doublet. It supports that Petzval used a thin lens model and a third-order calculation.

The stop shifting formulae [10] provide the amount of astigmatism $W_{222}$ aberration contributed by the doublets in the portrait objective, thin lens model. This is given by

$W_{222}=W_{222}^{A}+W_{222}^{B}+2 \bar{S} W_{131}^{B}$,

where $\bar{S}=\bar{y}_{B} / y_{B}$ is the stop shifting parameter, $\bar{y}_{B}$ and $y_{B}$ are the first-order chief and marginal ray heights at the rear thin doublet. $W_{222}^{A}=62 \lambda$ is the astigmatism contributed by the thin front doublet, $W_{222}^{B}=41.09 \lambda$ is the astigmatism contributed by the rear doublet when it is in contact with the front doublet and the aperture stop, and $W_{131}^{B}$ is the coma contributed by the rear doublet. For an aplanatic objective coma $W_{131}^{B}$ must be equal but opposite in sign to the coma contributed by the front doublet which is $W_{131}^{A}=45.12 \lambda$.

Assuming a flat medial astigmatic field curve we require

$W_{222}=-W_{220 P}$

By approximating the indices of refraction of the crown $n_{C}$ and flint $n_{F}$ glasses to 1.5 we can write for Petzval field curvature

$W_{220 P}=\frac{1}{4} \mathscr{W}^{2}\left(\frac{\phi_{A C}}{n_{C}}+\frac{\phi_{A F}}{n_{F}}+\frac{\phi_{B C}}{n_{C}}+\frac{\phi_{B F}}{n_{F}}\right) \cong \frac{1}{4} \frac{2}{3} \mathscr{W}^{2}\left(\phi_{A}+\phi_{B}\right)=\frac{1}{3}\left(W_{222}^{A}+W_{222}^{B}\right)$,

where $\phi$ stands for optical power, $A$ for the front doublet, $B$ for the rear doublet, $C$ for crown glass, and $F$ for flint glass. Then with the coma of the front doublet $W_{131}^{A}$ canceling the coma of the rear doublet $W_{131}^{B}$ Eq. 2 becomes,

$-2 \bar{S} W_{131}^{A}=-\frac{4}{3}\left(W_{222}^{A}+W_{222}^{B}\right)$

We can write the separation between doublets as $d=k \cdot f_{A}$; where $f_{A}$ is the focal length of the front doublet and $k$ is a scaling factor. Then the stop shifting parameter $\bar{S}$ can be written as

$\bar{S}=\frac{\bar{y}_{B}}{y_{B}}=\frac{\bar{u}_{B}}{y_{B}} d=\frac{\bar{u}_{B}}{y_{B}} f_{A} k=\frac{\bar{u}_{B}}{y_{A}} \frac{f_{A} k}{1-k}=-\frac{\bar{u}_{B}}{u_{B}} \frac{k}{1-k}$,

where $\bar{u}_{B}$ and $u_{B}$ are the chief and marginal ray slope before the rear doublet.

Then Eq. 4 becomes 
$\frac{k}{1-k}=-\frac{u_{B}}{\bar{u}_{B}} \frac{2}{3}\left(\frac{W_{222}^{A}+W_{222}^{B}}{W_{131}^{A}}\right)$

From the thin lens model we obtain $\bar{u}_{B}=\tan \left(16.5^{\circ}\right) \cong 0.296, u_{B} \cong-0.083, \frac{W_{222}^{A}+W_{222}^{B}}{W_{131}^{A}} \cong 2.28$, and then can write Eq. 6 as

$\frac{k}{1-k}=-\frac{u_{B}}{\bar{u}_{B}} \frac{2}{3}\left(\frac{W_{222}^{A}+W_{222}^{B}}{W_{131}^{A}}\right) \cong 0.43$

Eq. 7 has a solution of $k \cong 0.3$. Thus to have a flat medial astigmatic field curve the doublet separation is required to be about $1 / 3$ the focal length of the front doublet. If the separation is smaller there is not enough negative astigmatism contributed by the rear doublet to flatten the medial field.

Alternatively, by setting the distance between the doublets in the thin lens model to $1 / 3$ the focal length of the front doublet, and optimizing the rear doublet for a focal length of 144 linien, zero axial color, zero spherical and zero coma aberration, one finds that the ratio $\mathrm{W}_{222} / \mathrm{W}_{220 \mathrm{P}}$ becomes -0.79 . This ratio might indicate Petzval's choice for artificially flattening the field and is consistent with the ratio in the achromatic thin landscape lens discussed above. 